Jurdimas (Jurnal Pengabdian Ke pada Masyarakat) Royal

Vol. 3 No. 2, Juli 2020, hlm 147 - 154.

DOI: https://doi.org/10.33330/jurdimas.v3i2.516

ISSN 2622-3813 (Online)

Available online at https://jurnal.stmikroyal.ac.id/index.php/jurdimas

\title{
PELATIHAN APLIKASI POWERPOINT BAGI GURU DAN STAF SD NEGERI 010240 PEMATANG CENGKRING
}

\author{
Jeperson Hutahae an ${ }^{1 *}$, Zulfi Azhar ${ }^{1}$, Neni Mulyani ${ }^{1}$ \\ ${ }^{1}$ Sistem Informasi, STMIK Royal Kisaran \\ email: jepersonhutahean@gmail.com
}

\begin{abstract}
Teachers And Staff Of Elementary School 010240 Pematang Cengkring, Medang Deras Subdistrict are required to be dynamic towards the development of technology that is developing so rapidly that their students are able to develop by using applications that are already available such as Powerpoint applications. In using the Microsoft Powerpoint application by using a sliding percentage at SD Negeri 010240 Pematang Cengkring, Medang Deras District, this is not optimal due to the lack of teachers and staff's ability to present presentations using media presentations. This is from the STMIK Royal Kisaran Community Service Team (PKM) providing training to teachers and staff as an addition to the deepening of Microsoft Powerpoint material in order to provide skills to this application. This activity is carried out by preparing material, ensuring the place and supporting facilities, explaining theories about the material by way of direct practice, making student learning media, and also this activity is carried out in the form of lectures, discussions, and questions and answers in the classroom.
\end{abstract}

Keywords: computers; microsoft power points; presentations; teachers and staff; training

\begin{abstract}
Abstrak: Guru Dan Staf SD Negeri 010240 Pematang Cengkring Kecamatan Medang Deras dituntut bersifat dinamis terhadap perkembangan teknologi yang sangat berkembang pesat agar peserta didiknya mampu berkembang dengan menggunakan aplikasi yang sudah tersedia seperti aplikasi powerpoint. Dalam penggunaan aplikasi microsoft powerpoint dengan menggunakan slide presentase di SD Negeri 010240 Pematang Cengkring Kecamatan Medang Deras ini belum optimal dengan kurangnya kemampuan guru dan staf dalam menyajikan presentasi dengan menggunakan media presentasi. Hal ini dari Tim Pengabdian kepada masyarakat (PKM) STMIK Royal Kisaran memberikan pelatihan kepada guru dan staf tersebut sebagai penambahan pendalaman materi microsoft powerpoint agar memberikan skill pada aplikasi ini. Kegiatan ini dilakukan dengan mempersiapkan materi, memastikan tempat dan fasilitas pendukung, menjelaskan teori tentang materi dengan cara praktek langsung, pembuatan media pembelajaran siswa dan juga kegiatan ini dilaksanakan dalam bentuk ceramah, diskusi serta tanya jawab di ruangan kelas.
\end{abstract}

Kata kunci: guru dan staf; komputer; microsoft powerpoint; pelatihan; presentasi 
Available online at https:/jurnal.stmikroyal.ac.id/index.php/jurdimas

\section{PENDAHULUAN}

Sistem pendidikan dewasa ini telah mengalami kemajuan yang sangat pesat. Berbagai cara telah dikenalkan serta digunakan dalam proses belajar mengajar (PBM) dengan harapan pengajaran guru akan lebih berkesan dan pembelajaran bagi murid akan lebih bermakna. Dalam pelaksanaan sebagai seorang guru dengan melakukan pengajaran kepada siswa memerlukan suatu media pembelajaran sebagai suatu alat bantu dalam memberikan pelajaran dan pemahaman kepada siswa. Sampai saat ini media pembelajaran multimedia berbasis teknologi informasi dan komunikasi (TIK) belum berkembang dengan optimal di Indonesia. Salah satu kendala pengembangan media pembelajaran multimedia adalah kurang dikuasainya teknologi pengembangan media pembelejaran multimedia berbasis TIK oleh para pengajar, sehingga pengembangan materi pembelajaran multimedia berbasis TIK kurang optimal (Setiawan and Purnomo, 2016).

Proses pembelajaran di sekolah hendaknya disertai dengan media pembelajaran. Media pembelajaran yang paling banyak berkembang pada saat ini yaitu media pembelajaran berbasis komputer. Salah satu contoh media pembelajaran berbasis komputer yang paling sederhana dan mudah untuk dibuat guru adalah media pembelajaran berbasis Powerpoint (Ardiansah and Miftakhi, 2019).

Microsoft powerpoint merupakan aplikasi software yang dapat digunakan untuk menyampaikan materi berupa tulisan, gambar bentuk, foto, aneka warna dan jenis tulisan, fitur hyperlink, audio, video, dan animasi. Powerpoint merupakan media yang digunakan untuk menyampaikan poin-poin pokok dari materi yang kita sampaikan dengan fiturfitur yang menarik (Nurhidayati, 2019). Hanya ada satu dua guru yang pernah menggunakan namun belum memanfaatkan secara optimal fitur-fitur atau menu yang tersedia dalam program tersebut misal penggunaan gambar yang bergerak, memasukkan animasi, dan bahkan film. Hal ini tentu, membuat suasana belajar kurang interaktif dan cenderung membosankan karena kurang memotivasi peserta didik dalam menerima pembelajara. Alasan yang disampaikan oleh guru adalah karena mereka belum menguasai fitur-fitur yang ada pada program Microsoft power point (Poerwanti and Mahfud, 2018).

Microsoft power point digunakan sebagai media presentasi dan publikasi yang digunakan guru dalam menyampaikan materi pembelajarannya. Kegiatan belajar di sekolah akan memberikan keadaan yang lebih dinamis dan menarik siswa dengan penggunaan media interaktif beserta animasi seperti microsoft powerpoint. Powerpoint sudah banyak dimanfaatkan baik disekolah maupun diperguruan tinggi untuk proses belajar mengajar. Tetapi sosialisasi dan pemanfaatan program ini belum berlangsung luas, terutama oleh individu atau lembaga yang sebenarnya sangat membutuhkannya. Selain karena sumber daya manusia yang menguasai program ini masih sangat terbatas, ketersediaan lembaga lembaga kursus dan pelatihannya sangat langka (Ainin, Ahsanuddin, and Asrori, 2019). Salah satu hambatan proses belajar mengajar adalah keterbatasaan fasilitas yang dimiliki dan akses terhadap ilmu pengetahuan yang terus berkembang, antara lain keterampilan dalam penggunaan microsoft powerpoint yang terkait dengan proses belajar mengajar. Dalam penerapannya 
Jurdimas (Jurnal Pengabdian Ke pada Masyarakat) Royal

Vol. 3 No. 2, Juli 2020, hlm 147 - 154.

Available online at https:/jurnal.stmikroyal.ac.id/index.php/jurdimas

microsoft powerpoint dapat membantu pengajar dalam menyiapkan presentasi bahan ajar kepada siswa-siswi (Rusli, Winarso, and Putri, 2020).

SD Negeri 010240 Pematang Cengkring Kecamatan Medang Deras adalah salah satu Sekolah Dasar yang terletak di jalan S.M. Raja Gang Pendidikan RT: 01. RW:02 Kabupaten Batubara. Guru dan Staf kurang bisa memahami dan implementasi penggunaan aplikasi Microsoft Powerpoint sebagai slide presentase, sehingga perlu dilakukan bentuk kegiatan pelatihan. Dengan melaksanakan Pengabdian kepada Masyarakat berupa penyuluhan dan pelatihan ini diharapkan dapat memberikan pengetahuan guna meningkatkan keahlian sumber daya manusia bagi para guru agar lebih menguasai komputer khususnya powerpoint guna mendukung proses belajar dan mengajar sehingga para siswa lebih tertarik dan dapat aktif berpartisipasi (Shedriko, Setiawan, and Kusmayadi 2018).

\section{METODE}

Lokasi kegiatan pengabdian kepada masyarakat ini adalah SD Negeri 010240 Pematang Cengkring Kecamatan Medang Deras, dengan jumlah guru dan staf yang mengikuti kegiatan ini sebanyak 20 peserta yang dilaksanakan selama 2 hari di ruangan sekolah. Metode yang digunakan adalah Pelatihan, pengajarannya dengan memberikan contoh dasar secara teori dan praktek kepada peserta diiringi dengan praktek langsung peserta dalam mengikuti pelatihan ini. Hasil penilaian kemampuan peserta yaitu dengan cara melihat langsung hasil praktek yang dilakukan peserta oleh tim pengabdian kepada masyarakat. Penilaian kemampuan pesertra berdasarkan target yang ditawarkan dari kegiatan ini adalah melakukan pelatihan meningkatkan kemampuan guru dan staf dalam menyajikan presentasi intraktif melalui media microsoft powerpoint. Materi pelatihan meliputi tiga hal berikut yaitu, mengenal Microsoft Power Point, kedua membuat Laporan Hasil Belajar Siswa Dengan Microsoft Office Power Point dan ketiga membuat Media Pembelajaran Siswa Dengan Microsoft Office Power Point.

\section{PEMBAHASAN}

\section{Menjalankan Microsoft Powerpoint}

Cara pertama yaitu dengan mengklik tombol 'Start' lalu cari menu 'All Program' dan pada bagian menu 'Microsoft Office' pilih menu 'Microsoft Office Powerpoint'.

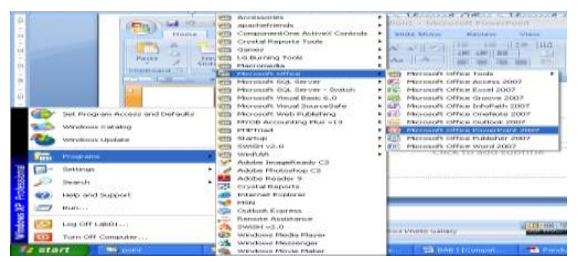

Gambar 1 Melalui Menu Aplikasi Program

Cara kedua yaitu dengan mengklik tombol 'Start' pada aplikasi windows kemudian pilih menu 'Run' lalu ketikkan kata 'powerpoint' pada kotak kosong yang tersedia lalu klik 'Enter'.

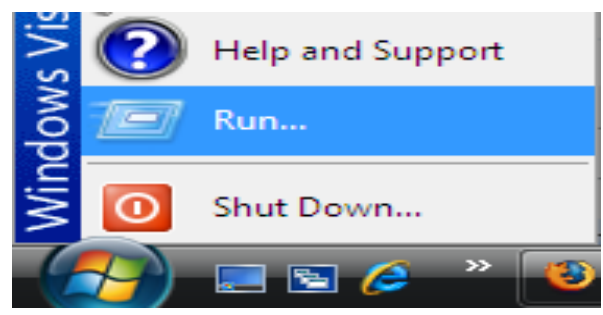

Gambar 2 Tampilan Dalam Menggunakan Run 
Available online at https://jurnal.stmikroyal.ac.id/index.php/jurdimas

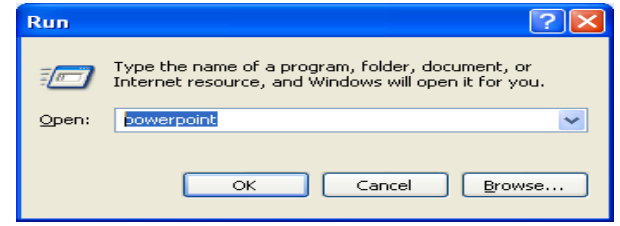

Gambar 3 Tampilan Dalam Menu Run Membuka Aplikasi Power Point

\section{Cara Buat Persentasi Baru}

Kita bisa mulai presentasi baru yang kosong dari slide, template, ada presentasi, atau Word outline.

Untuk membuat presentasi baru yang kosong, langkah-langkah sebagai berikut yaitu dengan melakukan pengklikan pada tombol 'Office Button' lalu pilih menu 'New' kemudian pilih menu 'Blank Presentation'. Setelah itu pilih menu 'Create untuk memulai membuat slide presentasi baru pada microsoft power point.

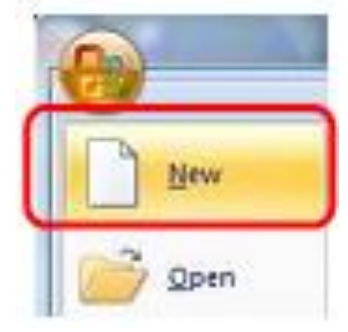

Gambar 4 Memilih Menu New Dalam Membuat Slide Presentasi Baru

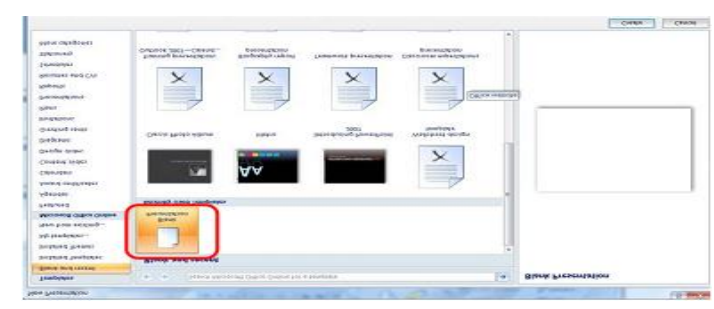

Gambar 5 Memilih Menu Blank Presentation Dalam Membuat Slide Presentasi Baru

Kemudian akan muncul jendela presentasi di layar monitor, jendela presentasi yang muncul ini adalah merupakan slide judul presentasi.

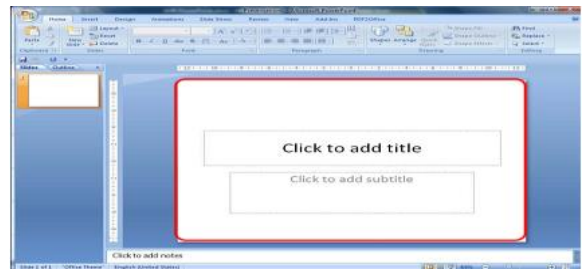

Gambar 6 Slide Judul Presentasi

Kemudian setelah itu kita akan membuat slide kedua caranya yaitu pilih 'New Slide' lalu klik pada menu 'Title \& Content'

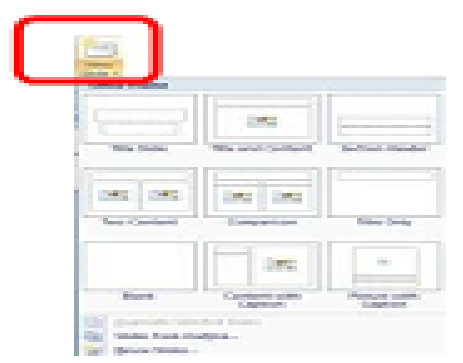

Gambar 7 Memilih Menu Title \& Content

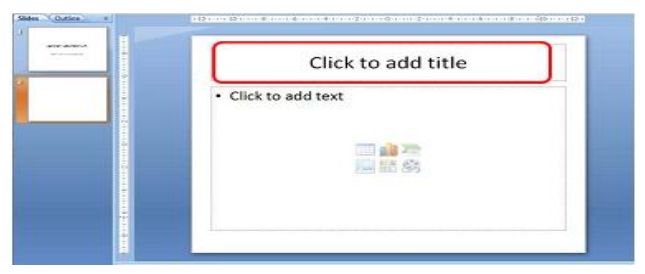

Gambar 8 Membuat Slide Kedua

Untuk langkah selanjutnya menambah slide yang ke 3 dengan mengklik pada menu 'New Slide' lalu pilih 'Two Content lalu klik 'New'.

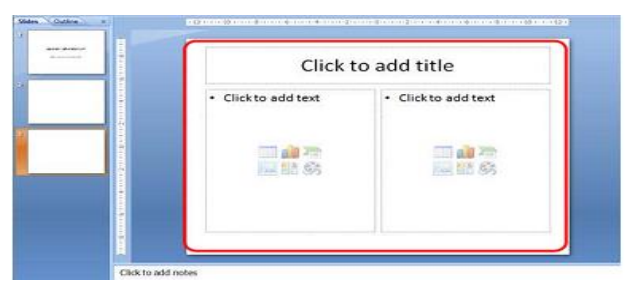

Gambar 9 Memilih Slide Ketiga menggunakan Two Content

Kemudian simpan hasil kerja slide tersebut , dengan mengklik 'Microsoft Office Button' lalu pilih menu 'Save' atau dengan menekan 
Available online at https:/jurnal.stmikroyal.ac.id/index.php/jurdimas

tombol $C t r l+S$. Lalu beri nama file yang ingin kita simpan tersebut.

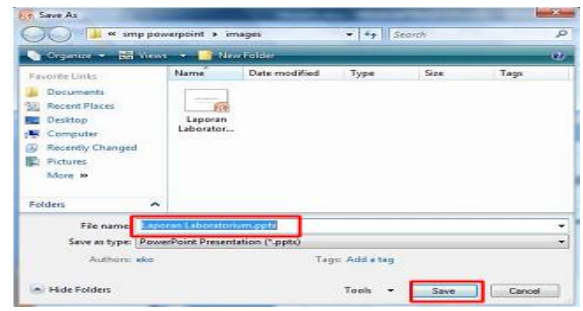

Gambar 10 Menyimpan Hasil Slide Pada Microsoft Power Point

\section{Menyimpan Dengan Nama Lain}

Setelah hasil slide yang telah kita buat selesai maka harus disimpan hasil kerja kita tersebut dalam folder di komputer. Untuk menyimpan file tersebut dengan cara Klik 'Microsoft Office Button' lalu pilih ' Save As'. Untuk menyimpan file tersebut ada beberapa tipe data yang bisa kita pilih yaitu untuk pptx adalah untuk ekstensi Powerpoint 2007, ppt adalah untuk powerpoint 97-2003, pot adalah pemyimpanan template standar, gif adalah penyimpanan dalam format gambar (gif) dan jpg adalah penyimpanan dalam format gambar (jpg) lalu klik 'New'.

\section{Memulai Presentasi Dari Template}

Untuk memulai slide presentasi dari template yaitu dengan mengklik 'Office Button' lalu pilih 'New'. Setelah itu maka terbuka Jendela 'New Presentation' lalu pilih 'Installed Template' lalu klik 'Classic Photo Album'. Setelah itu secara otomatis akan membuka sebuah presentasi di layar monitor kita. Ini merupakan presentasi yang telah disediakan Microsoft Powerpoint 2007 yang bisa kita gunakan sebagai dasar membuat presentasi. Untuk berpindah antar slide klik bagian kiri ini lalu simpan hasil kerja anda dengan nama 'latihan1.pptx' kemudian klik 'Save'.

\section{Menutup Presentasi}

Untuk menutup hasil presentasi anda, klik tanda close $(X)$ di pojok kanan atas. Atau bisa juga dengan menekan tombol 'Quick Access Button' lalu pilih 'Close'.

\section{Pengaturan Tampilan Kerja Layout}

Pengenalan Beberapa Tampilan

Dengan menggunakan beberapa menu terdiri dari, Tampilan Area Outline, Tampilan Slide Sorter, Memilih Dan Mengganti Layout/Tampilan Slide, Menggunakan Themes Slide, Menggunakan Themes Multiple Themes Dalam Satu Presentasi dan Mengedit Format Themes

\section{Menambah Animasi}

Menambahkan animasi dalam presentasi dengan menggunakan beberapa pengaturan seperti Mengatur Animasi Berjalan Secara Otomatis, Perpindahan Slide Berjalan Secara Otomatis, Mengatur Efek Perpindahan Slide.

\section{Anatomi Power Point}

Anatomi dasar slide dengan melakukan pembuatan presentasi seperti pembuatan kontent presentasi dengan yang penting saja yang tidak panjang dalam membuat suatu makalah. Waktu durasi presentasi tidak perlu terlalu lama disesuaikan dengan waktu yang dijadwalkan. Isi pada pelatihan menggunakan bentuk yang menarik.

Pada penggunaan template yang sudah ada, yaitu dengan menggunakan menu pada 'Microsoft 
Available online at https:/jurnal.stmikroyal.ac.id/index.php/jurdimas

Office Button' lalu cari menu 'New
Presentation' Ambil menu lalu
'Installed Templates'. Setelah itu
lakukan pilih Layout Slide,
Memasukkan Ilustrasi, Memasukkan
Obyek Teks dan Mengatur
Background.

\section{Menggunakan Objek pada Word juga pada Ms Excel}

Pengambilan data objek pada MS

Word juga MS Excell, yaitu dengan cara memilih data objek pada MS Word ataupun Excell kemudian ambil menu 'Copy' pindahkan pada Power Point, pada menu 'Tab Home' ambil 'Menu Paste'.

\section{Menggunakan Perpindahan antar Slide}

Transisi diantara slide dapat diatur dengan bentuk-bentuk tertentu. Dengan menggunakan event tertentu, dengan mengklik kiri mouse, lalu menekan tombol enter, gunakan tombol cursor arah dan tombol spasi.

\section{Penggunaan Multimedia}

Penggunaan multimedia adalah seperti berikut, menggunaan bentuk multimedia seperti audio, video, animasi, text, grafik dan image. Proses penyimpan dilakukan secara digital dan memberikan efek animasi. Penggunaan multimedia dengan slide presentasi yang sederhana berformat movie ataupun sound.

\section{Bentuk Pada Movies Serta Sounds}

Penggunaan file pada bentuk movie dan sound dapat dilakukan dengan memilih menu 'Tab Insert' lalu menggunakan Grup Menu Media Clips dan masukkan file Movie ataupun Sound pada slide tersebut.

\section{Pembuatan Animasi}

Pada slide presentasi akan menjadi lebih menarik dengan membuat animasi dengan mengisi gambar ataupun teks. Pada menu 'Tab Animations' ambil Grup Menu Animations lalu menu 'Custom Animation'. Pada menu 'Add Effect' untuk penambahan bentuk animasi. Kelompok animasi dasar ada 4 dimana setiap animasi mempunyai beberapa bagian jenis animasi lagi.

\section{Presentasi Non Linear ( Interaktif )}

Secara umum dari sudut pandang perpindahan/transisi antar slide, jenis presentasi dapat dibagi menjadi 2 yaitu:

Presentasi Linear dan Presentasi Non Linear ( Interaktif )

Presentasi linear adalah jenis presentasi yang perpindahan antar slidenya berjalan secara linear dan berurutan, setelah slide 1 ke slide 2 terus ke slide 3 dan begitu seterusnya. Jenis presentasi ini tidak memungkinkan interaksi dengan user (yang melihat presentasi).

Berbeda dengan presentasi linear, perpindahan antar slide pada presentasi non linear bisa tidak berurutan, misal dari slide 2 bisa saja meloncat ke slide 4 dan seterusnya. Untuk bisa meloncat ke slide tertentu di perlukan navigasi yang ditujukan ke pada user sehingga user diberikan pilihan untuk bisa menuju ke slideslide yang diinginkan, inilah kenapa jenis presentasi non linear disebut juga presentasi interaktif. Untuk lebih memahami konsep presentasi non linear seperti sebagai berikut ini yaitu dengan membuat 3 slide. Pilih 'Tab Insert', di slide 1 sorot tulisan pada judul file kita, di grup menu Links pilih 'Action'. Pada menu 'Action 
Available online at https://jurnal.stmikroyal.ac.id/index.php/jurdimas

Setting' atur properti di tab 'Mouse Click' , pada 'Action on Click' pilih 'Hyperlink to Slide', kemudian pilih Slide ke 2. Pada bagian lain, buatkan ke Slide no. 3. Pada Menu Utama buatkan pada Slide 2 dan 3, lakukan pada First Slide. Untuk melihat hasil lalu tekan tombol F5, lakukan pengaturan dengan 'Action Setting'.

\section{Tab Mouse Over}

Fungsinya - fungsinya hampir sama pada tab 'Mouse Click' tetapi jika pada 'Mouse Click' aksi terjadi ketika obyek di klik maka pada even 'Mouse Over' jika pointer mouse berada di atas obyek.

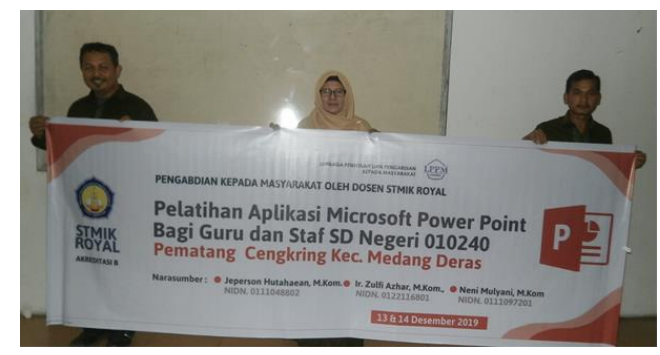

Gambar 11 Peneliti Dari Dosen STMIK Royal Pada Pelatihan Microsoft Power Point di SDN 010240 Pematang Cengkring Kec. Medang Deras

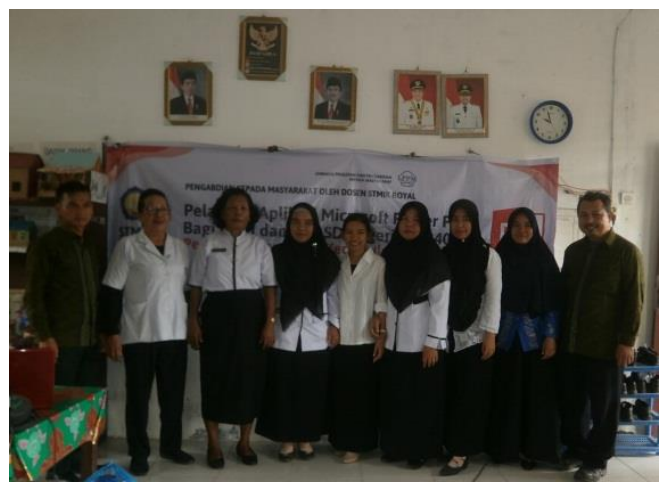

Gambar 12 Para Guru dan Staf di di SDN 010240 Pematang Cengkring Kec. Medang Deras Pada Pelatihan Microsoft Power Point

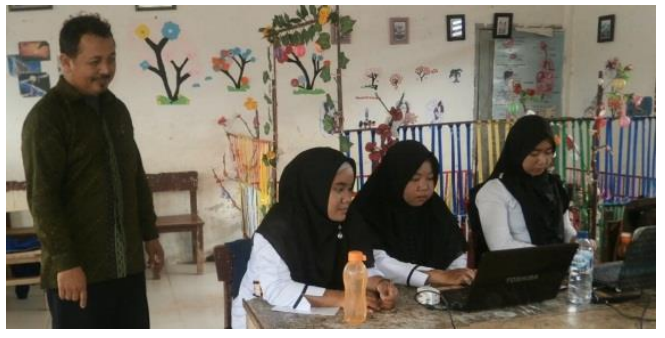

Gambar 13 Dosen STMIK Royal Kisaran memberikan Pelatihan kepada Guru dan Staf di di SDN 010240 Pematang Cengkring Kec. Medang Deras

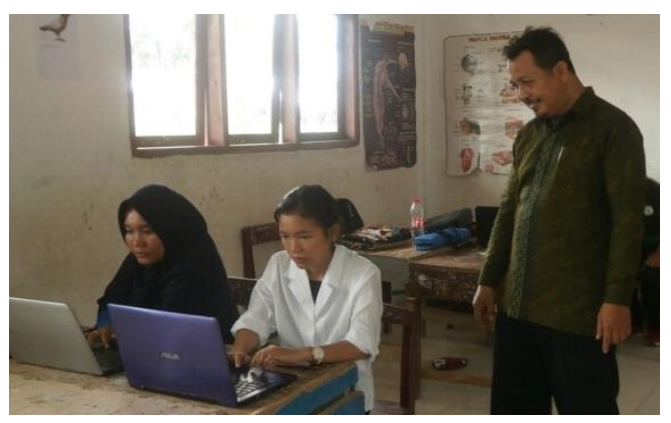

Gambar 14 Dosen STMIK Royal Kisaran memberikan Pelatihan kepada Guru dan Staf di di SDN 010240 Pematang Cengkring Kec. Medang Deras

\section{SIMPULAN}

Dari hasil kegiatan pengabdian kepada masyarakat yang dilakukan dapat disimpulkan bahwa hasil penilaian kemampuan peserta rata-rata sekitar 95 $\%$ dan telah menguasai dan memahami materi Microsoft Powerpoint yang disampaikan. materi yang disampaikan kepada peserta mencapai semua konsep pada aplikasi. Disamping itu peserta juga dapat mengimplementasikan ribbon ribbon yang ada pada Microsoft Powerpoint dan mampu mengimplementasikan penggunaan animasi yang ada pada Microsoft Powerpoint. 
Jurdimas (Jurnal Pengabdian Kepada Masyarakat) Royal

Vol. 3 No. 2, Juli 2020, hlm 147 - 154.

DOI: https://doi.org/10.33330/jurdimas.v3i2.516

Available online athttps:/jurnal.stmikroyal.ac.id/index.php/jurdimas

\section{DAFTAR PUSTAKA}

Ainin, Moh, Mohammad Ahsanuddin, and Imam Asrori. 2019. "Pelatihan Powerpoint Bagi Guru Bahasa Arab MTs Kota Dan Kabupaten Kediri." Al-khidmah.

Ardiansah, Feri, and Diah Rina Miftakhi. 2019. "PELATIHAN

PEMBUATAN

MEDIA

PEMBELAJARAN INTERAKTIF

BERBASIS POWERPOINT BAGI

TENAGA PENDIDIK PAUD

HIMPAUDI KECAMATAN

GABEK KOTA

PANGKALPINANG Feri

Ardiansah 1, Diah Rina Miftakhi

2." Jurnal Pengabdian Pada Masyarakat.

Nurhidayati, Nurhidayati, Imam Asrori, Mohammad Ahsanuddin, and $\mathrm{M}$. Wahib Dariyadi. 2019. "PEMBUATAN MEDIA

PEMBELAJARAN BERBASIS

POWERPOINT DAN

PEMANFAATAN APLIKASI

ANDROID UNTUK GURU

BAHASA ARAB." Jurnal

KARINOV.
Poerwanti, Jenny Indrastoeti $\mathrm{S}$, and Hasan Mahfud. 2018. "Optimalisasi Penggunaan Media Pembelajaran Interaktif Dengan Microsoft Power Point Pada Guru-Guru Sekolah Dasar." JPPM (Jurnal Pengabdian dan Pemberdayaan Masyarakat).

Rusli, Muhammad, Edy Winarso, and Darani Putri. 2020. "Pelatihan Microsoft Powerpoint Dasar Bagi Guru Guru Paud Kabupaten Bekasi." Jurnal Pengabdian kepada Masyarakat.

Setiawan, Budi, and Endro Purnomo. 2016. "PELATIHAN MEDIA PEMBELAJARAN MULTIMEDIA DENGAN POWERPOINT DAN WONDERSHARE UNTUK PENGEMBANGAN SOFT SKILLS SISWABAGI GURU SD \&TK1)." Warta LPM.

Shedriko, Shedriko, Heri Satria Setiawan, and Kusmayadi Kusmayadi. 2018. "Pelatihan Perangkat Lunak Powerpoint Untuk Meningkatkan Kinerja Guru Di SD Dan SMP 19 Muhammadiyah Sawangan Depok." Jurnal PkM Pengabdian kepada Masyarakat. 